\title{
Police Attitudes in England to Return Interviews, in Repeat Missing Person Cases
}

\author{
MICHAEL F. HARRIS* and KAREN SHALEV GREENE \\ Institute of Criminal Justice Studies, University of Portsmouth, Portsmouth, UK
}

\begin{abstract}
The aim of this article is to examine the attitudes of English police officers to return interviews of people who are reported missing repeatedly (e.g. three times or more). In addition to a brief police 'Safe \& Well Check' a return interview is also carried out by a police officer ${ }^{1}$ and seeks to find out where people went and why, in order to identify potential risks to their safety and whether they experienced harm whilst they were missing. A mixedmethods survey of 50 constables from one police force in England ran in March 2014, using quantitative and open qualitative questions. Key themes that emerged were individual frustration at repetition, negativity around usefulness of the interviews, a challenge to involve third sector partners, and development areas in training. Statistical significance was found in variables relating to officer experience and gender, against views on interviewing missing people. The article looks at the limited existing literature and makes recommendations about best practice with return interviews, advocating a multi-agency approach to improve interventions, and better training to improve positivity towards missing people.
\end{abstract}

Key words: missing people; public protection; police interviews; police culture; gender

\section{INTRODUCTION}

This article sets out the wider picture on missing people and delves deeper into the experiences of individual police officers regarding interviewing those who return after going missing repeatedly. In England and Wales, the police service defines a missing person as 'anyone whose whereabouts is unknown, whatever the circumstances of the disappearance' (Association of Chief Police Officers [ACPO], 2013). 'Repeat' missing people for the purpose of this article are those missing three times or more. They represent areas of risk and challenge to frontline police resources. This is because a number of enquiries are required, such as searching addresses, trawling hospitals, visiting friends and family, and possibly

\footnotetext{
*Correspondence to: Michael Fraser Harris, Institute of Criminal Justice Studies, University of Portsmouth, Portsmouth, UK.

E-mail: michael.harris@port.ac.uk

${ }^{1}$ From October 2015, Local Authorities made legally responsible for children, but compliance varies
} 
searching large open spaces. This might involve uniform response officers, neighbourhood policing staff, dog handlers, specialist search teams, and detectives.

The police service in the UK is organised into 43 geographical forces, which loosely resemble the various counties. In addition, there are support forces such as the British Transport Police, who patrol the railway network. In support are newly revised countrywide services, such as the National Crime Agency. In terms of missing people, these strategic services focus on organised criminality, such as people trafficking.

In 2013/14, the UK police recorded 307,418 missing person reports (NCA, 2015). Repeat incidents during the same period accounted for over a third of missing cases (p. 13). Shalev and Pakes (2013) estimated the cost of an average investigation to be up to $£ 2,415$. The police response will be dependent on what risk is attached to their disappearance. If there is low risk to the person or the public ( $23 \%$ of cases nationally), there will be routine phone-based and computer enquiries. If there is high risk to life (12\% of cases nationally), the response will involve many resources on an urgent basis. Nationally, two-thirds of cases are classified as medium risk (NCA, 2015), because there are risks but the danger is not assessed as life-threatening.

At the end of any missing person investigation, a return interview should normally take place to build on the brief police 'Safe \& Well Check', which simply established whether the person was okay. Most police forces only conduct return interviews for children, but the English police force investigated in this study conducts interviews with children and some adults. These interviews will consist of a face-to-face discussion with the missing person. The value of this interview is they offer an opportunity to explore why they left, including identifying any underlying issues such as finance or health matters. Interviews may also establish where they went and what they did, providing clues to their behaviour, and offering opportunities to unpick the relevance of their journey. This may lead to how another 'missing' incident might be prevented; therefore, interviews are crucial to help build a picture about the missing incidence. Across England and Wales, return interviews are usually conducted by police officers, but increasingly they may be performed by support workers employed by the local council, especially where children are concerned. $^{2}$ In these cases, the police should be updated with any relevant information as part of local safeguarding procedures.

This article argues that the police service in England and Wales spend significant time and resources investigating people repeatedly reported missing, yet very little research explores how police return interviews are conducted when people are found. Moreover, it is argued that even less is known about the police officers conducting return interviews, in terms of their attitudes to return interviews and how this might impact on reducing repeat episodes and mitigating harm. Also, officers' role, gender, age, training, and experience, relating to return interviews, are unknown in the UK.

Existing research about missing people tends to focus on risk, missing children, or fatal outcomes. The bulk of research has been on young missing people (Newman, 1989; Payne, 1995; Biehal, Mitchell, \& Wade, 2003; Brown \& Wain, 2009; Rees, 2011). Many young people in care were not missing but were simply absent without staff permission. Payne argues this was a major issue, particularly relating to repeat instances (1995, p. 342). A recent revision of the definition by ACPO now includes an 'absent' category, where people not at their expected location with no risk factors involved could be 'held on file' for up to

${ }^{2}$ Prior to this study, from October 2015, Local Authorities made legally responsible for children, but compliance varies 
24 hours (ACPO, 2013). This aimed to alleviate the strain on police resources in response to expressed attitudes by officers, that there was a lack of proportionality in investigations. However, Payne (1995) and Rees (2011) assert that there is considerable risk when young runaways go missing, and so, return interviews are important. Only $2 \%$ of runaways proactively approached the police on their return from being missing (Rees, 2011, p. 18), which may challenge whether officers are the correct people to conduct return interviews for them.

There is scant literature on police officers' attitudes to missing people. In 2013, Bayliss and Quinton interviewed UK police officers and staff, finding that they were critical of care homes and repeatedly missing people, and felt helpless. Because they only interviewed 13 uniformed police officers, their findings cannot be generalised. A pilot study in Scotland found that police officers' attitude to missing people improved, when they were dispatched to fewer low-risk cases. However, they did not prove consistent long-term attitude change towards missing people, but it may be important to still consider (Burgess et al., 2010).

Hayden and Goodship (2013) found frustration by UK officers at criminalising missing children who were simply 'pushing boundaries', and that officers reported being more risk-adverse than social workers. They found that attitudes of individual officers were variable, and 'streetwise' was an accepted term for vulnerable kids (p. 14). This attitude could indicate that return interviews for children may not be valued by officers.

There is very little literature on return interviews themselves. Previous studies suggest that return interviews in England and Wales are not performed in all missing person cases. When a return interview is carried out, the information that is obtained often has little in-depth data about where missing people went and what experiences they were subjected to (Tarling \& Burrows, 2004; Shalev, Schaefer, \& Morgan, 2009; Newiss, 1999, 2011). Hedges (2002) acknowledges that return interviews are a difficult process but found patchy recording practices. He advocates return interviews can considerably reduce repeat cases but provides no evidence of this. He also advises interviews should be by dedicated police officers or the third sector, to build trust, and that child abuse needs scrutiny (p. 30). Fyfe, Stevenson, and Woolnough (2015) interviewed 21 police officers and highlighted positivity from officers involved in return interviews where officers wanted to offer a good service (p. 11). Yet, it is unclear how many interviewees were frontline constables, and investigation of officers' attitudes appeared limited.

Holmes (2014) recommended all returned missing people in the UK be interviewed and police officers conducting interviews should safeguard and signpost to help. Young people should have a consistent interviewer, and return interview data should be collated for a shared understanding of specific needs and possible required interventions, which will help safeguard the missing person upon their return. She also argues that interviews should be by trained independent, non-statutory staff and that a multi-agency partnership was key to reconnect missing people. The issue of training is important because the interviewer needs to obtain the best value from the interaction. The Independent Police Complaints Commission, who oversee police forces in England and Wales, consistently highlights training issues when things go wrong, such as in a 'Learning the Lessons' bulletin, on searching for a vulnerable missing person (IPCC, 2014). Moreover, training could lead to better handling of return interviews, in order to reduce repetition, and thus risk. Which variables make return interview training work, will require further research. 
There is a discernable volume of literature on police interview training. Themes that some authors highlight included a sense of disengagement from training by the officers unless it speaks to them on a pragmatic level (Haberfeld, 2002). Of more direct relevance to specific job-related police interview training, Dando and Bull (2011) revealed a significant advantage for officers in detecting both deceivers and truth tellers in suspect interviews, when specifically trained to a tactical model. Conversely, Memon, Bull, and Smith (1995) found no differences in witness performance when 38 officers were trained to use cogitative interviewing as compared with a control interview technique. Feedback from interviewers and a study of interview transcripts suggested that the cognitive training (successful in previous studies) had little impact on the interviewing style of experienced officers and that the cognitive techniques were not used appropriately.

Snook, Luther, Quinlan, and Milne (2012) found that despite training, less than $1 \%$ of interview questions asked by Canadian police officers were open-ended, despite the longest interviewee responses being obtained from open-ended questions. Closed yes-no and probing questions composed approximately $40 \%$ and $30 \%$ of the questions asked, respectively. Only officers in approximately $14 \%$ of the interviews requested a free narrative. The way these authors' findings might impact on targeted training for police return interviews is therefore debatable.

Police interview training in England and Wales tends to focus on suspect questioning. This model is meant to involve asking an early open question to establish the interviewee's narrative and then dividing this into chunks for further probing. The interviewer then moves onto their own agenda, exploring topics they want (or need) to cover. This structured approach, culminating in a challenging, adversarial phase towards the end of the interview, is fairly single-minded as it is usually structured by the needs of the police investigation and points to prove in legal settings.

Very little thought is given to other structured approaches, such as Watzlawick (1966). He explored family counselling with structured interviews that specifically did not apportion blame or stigma. Instead, family members were individually invited to share their view with the interviewer on what they considered 'wrong' within the family unit. The family was then brought back together as the 'unit' and told each member that felt something was wrong, which they could share if they wanted. The interviewer then knowingly observed the discussion through a one-way window. The strength of this approach is that it 'cuts to the chase' so to speak, but in a way that empowers the respondent to feel their opinion is valued, whilst not making assumptions about what the problem might be.

Watzlawick asserts that this mitigates 'scapegoating' whilst establishing a family discussion that might be built upon in further counselling without necessitating hours and hours of analysis. If applied to the missing person return interview, there could be useful benefits between the stakeholders involved (such as family, school, and support workers), especially if repeat episodes need to be addressed.

When interviews are carried out by a police officer, there is a danger that they will fall disproportionately to female officers, because of a traditional police culture of aligning women officers with so-called 'soft' policing. Fielding (1994), Reiner (2000), and Westmarland (2001) identified marginalisation of female officers into 'stereotypical roles'. They found that women were over-represented in child safety and public protection departments, and under-represented in specialist roles such as firearms and roads policing. Therefore, this study also explores gender differences in attitude and experience of officers conducting return interviews. 
Alys, Massey, and Tony (2013) highlight the uneasy fit of missing person investigations against the crime-fighting function and stress 'very little is known about how police officers make decisions' (p. 147). They call for a revisit on stereotypical police attitudes to missing people through empirical research, to identify which attitudes need to be targeted. Therefore, the aim of this study is to critically examine attitudes of police officers around how often return interviews are performed, importance they place on interviews, their perceived usefulness, and training issues.

\section{METHODOLOGY}

The study was carried out during March 2014 in a large city within an English police force. Access to officers was made possible through an introduction at chief officer level within that force. Officers were invited to complete an anonymous Web-based survey, emailed to constables through a generic force email address.

The mixed-methods online survey comprised 24 closed and open-ended questions, and six Likert scale questions to measure attitude. For these, (1) was strongly agree and (5) was strongly disagree, or (1) was very engaged (1) and (5) was very unengaged. Each Likert scale had an open question, to elicit reasons for the response. The Likert questions were tested for reliability, returning a very respectable Cronbach's alpha score of 0.708. IBM SPSS (IBM, Armonk, NY, USA) was used to analyse closed question responses and Likert replies. Kolmogorov-Smirov and Shapiro-Wilk tests of normality governed analysis. Mann-Whitney $U$ tests were used to report the Likert $p$-values, because these were non-parametric. Fisher's exact test was used to report all other $p$-values, because of cell counts. All values are two-sided.

Microsoft Excel (Microsoft, Redmond, WA, USA) was used for thematic content analysis of free text responses, to identify key issue. First, all free text comments by respondents were scanned and key words/phrases extracted, to exclude passive or article words. Statements that did not directly address the question were removed but kept elsewhere to provide comment on attitudes. Key words/phrases were then input into Excel once, eliminating repetition. A common sense approach was taken so that 'mitigate harm' was taken to be the same as 'reduce hurt'. Words/phrases were then tallied to identify the top 10 responses. These most popular responses were then synthesised into a single paragraph, to highlight the real issues for the researchers. They were also placed into three key theme columns, within another Excel worksheet, to highlight the wider issues. For example, in response to the question on why it was important to conduct a return interview for an adult, three theme columns emerged: 'intelligence gathering' (which contained responses such as 'locate in the future'); "negative comments or "depends"' (which contained responses such as 'waste of time'); and 'welfare or health' (which featured replies such as 'drugs' or 'alcohol'). All free text remarks were reported as sic.

A sample of 50 officers was gained from the survey, giving a $12 \%$ response rate from the population of 433 constables. Towards the end of the Web-based survey, eight officers stopped replying to questions.

\section{RESULTS}

The participant population comprised $76 \%$ male officers $(n=38)$ and $24 \%$ female officers $(n=12)$. This closely matched the make-up of constables in the city under investigation, as 


\section{F. Harris and K. Shalev Greene}

reported by the human resources department, of $75 \%$ male and $25 \%$ female. This mirrored the national picture of $27 \%$ being female officers (Home Office, 2013).

Sixty per cent of officers were aged 36 years or over $(n=30)$, whilst $40 \%$ were under 36 years old $(n=20)$. Again, this matched the city's constable population of $68 \%$ and $32 \%$, respectively. It was statistically significant that female officers $(n=12)$ were twice as likely as male colleagues $(n=6)$ to be under 36 years of age, where $p=0.04$.

Fifty-six per cent $(n=28)$ of officers reported being non-graduates, whilst $44 \%(n=22)$ reported having degree or postgraduate qualifications. The majority of officers $(60 \%$, $n=30$ ) had 10 years or more service. Taking all the demographics of officers into account, it is argued that the study sample is representative of the constable population in the city visited. It may be representative of other cities too, but because local arrangements and training may come into play, further research is recommended.

The results of the study show that the majority of police officers in the sample (68\%) had experience conducting more than three return interviews for missing people. A significant proportion of officers $(48 \%, n=24)$ reported more than half of their interviews involved repeatedly missing people. This shows the prevalence of repeat cases in the officers' work experience and supports the national statistics (NCA, 2015).

The greatest burden for return interviews of missing people is borne by officers with the least experience (Table 1). Most of the officers with less than 10 years service $(85 \%, n=17)$ had conducted three or more return interviews, where $p=0.05$. Veteran officers accounted for half of all cases where return interview experience was low.

Nearly all officers in the sample $(90 \%, n=38)$ were not trained in conducting return interviews for missing people. These officers had not read the national policy either, where $p=0.03$. The four officers who were trained in how to conduct return interviews all had 10 years service or less, where $p=0.05$ (Tables 2 and 3). These officers had also all read

Table 1. Length of service/number of return interviews

\begin{tabular}{lcc}
\hline & \multicolumn{2}{c}{ No. of interviews } \\
\cline { 2 - 3 } Service & $<3(\%)$ & $3+(\%)$ \\
\hline 10 years or less & 15 & 85 \\
$11-15$ years & 33 & 67 \\
16 years or more & 50 & 21 \\
\hline
\end{tabular}

Table 2. Length of service/trained

\begin{tabular}{lcc}
\hline Service & Trained $(\%)$ & Untrained (\%) \\
\hline 10 years or less & 24 & 76 \\
$11-15$ years & 0 & 100 \\
16 years or more & 0 & 100 \\
\hline
\end{tabular}

Table 3. Read ACPO Policy/read Force Policy

\begin{tabular}{lcc}
\hline Read ACPO Policy & Read Force & Not read Force \\
\hline Yes $(\%)$ & 61 & 20 \\
No $(\%)$ & 21 & 71 \\
\hline
\end{tabular}

ACPO, Association of Chief Police Officers. 
the national policy. If the officer had not read the national policy, over two-thirds $(n=20)$ had not read their local policy either, where $p=0.01$.

Nearly all officers in the sample $(98 \%, n=41)$ were trained in the police national interview model for suspects. However, the majority of officers $(76 \%, n=38)$ were not trained in interviewing vulnerable adult and child witnesses. Only a third of these untrained officers $(n=12)$ had read the national missing person policy, where $p=0.03$. All the vulnerable adult and child witness-trained officers had read national policy.

The majority of officers $(56 \%, n=24)$ either agreed or strongly agreed that it was important to conduct a return interview for adult missing people. The mean response was 2.5 (standard deviation 1.239). A popular reason for supporting interviews was 'the return interview helped locate a missing adult in the future' $(n=16)$. No officer mentioned safeguarding in responses about adults. A significant minority $(28 \%, n=12)$ disagreed or strongly disagreed an interview for adults was needed (Chart 1). A key reason officers gave against interview importance was that it was 'a waste of time, unimportant and nothing achieved as repeatedly go missing' $(n=10)$. These officers further reflected that 'Some... cannot be helped and one day, yes they may turn up dead but we cannot resource a gold service to these "types", (Table 4).

Officers were more positive about the importance of return interviews for children. The majority of officers in the sample strongly agreed that it was important for a child to have a return interview. The mean response was 2.3 (standard deviation 1.286). Popular reasons for supporting interviews was that they provided 'intelligence for locating children in the future' ( $n=15)$ and 'safeguarded, offered help and protected (the) vulnerable' $(n=12)$. A

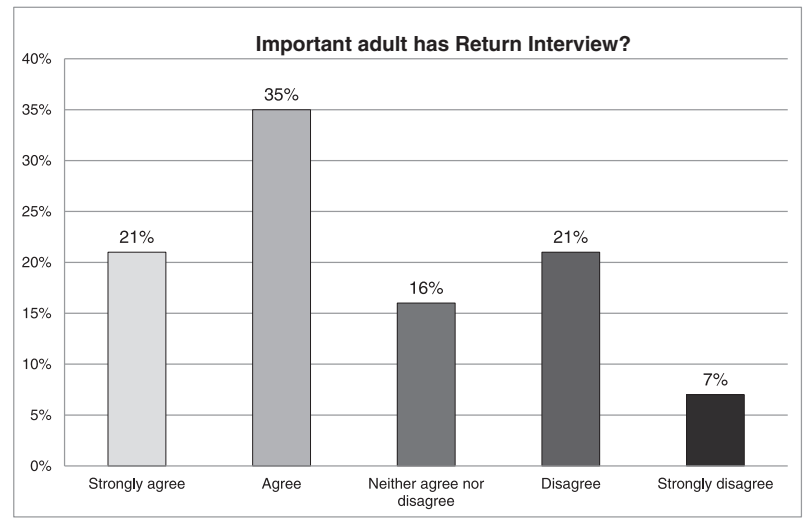

Chart 1. Important adults have return interview?

Table 4. Importance of return interview for adult-free text themes

\begin{tabular}{lll}
\hline $\begin{array}{l}\text { Intelligence gathering } \\
\text { about circumstances }\end{array}$ & \multicolumn{1}{c}{$\begin{array}{c}\text { Negative comments } \\
\text { or saying it depends }\end{array}$} & Welfare or health of person \\
\hline $\begin{array}{l}\text { Prevent repeat } \\
\text { Why/where went }\end{array}$ & $\begin{array}{l}\text { Waste of time } \\
\text { Misper does not think missing } \\
\begin{array}{l}\text { Recument } \\
\text { Leduce number of missing people }\end{array}\end{array}$ & $\begin{array}{l}\text { Drugs/alcohol } \\
\text { Dental health }\end{array}$ \\
\hline
\end{tabular}


significant minority $(23 \%, n=10)$ disagreed or strongly disagreed an interview for children was needed (Chart 2). A key reason officers gave against interview importance was that children were 'unprepared to provide relevant information, rarely engage' $(n=8)$. These officers further reflected that 'children could well be at immense risk of exploitation or harm.. but I have never had one... disclose anything to me' and also that 'after a child has gone missing three times, a return interview is a fairly pointless exercise' (Table 5).

Experience at return interviews for missing people reduced police officers' positivity about their usefulness. Only the officers that had conducted three or more return interviews strongly disagreed they were important. For adults, statistical significance was $p=0.04$. For children, it was $p=0.02$.

When officers were asked who should conduct return interviews, responses differed by gender of the officer. Female officers did not select a parent/guardian/non-police worker as an interviewer at all. Instead, the majority $(73 \%, n=8)$ selected a sworn police officer to interview an adult, where $p=0.05$. However, nearly half of male officers leant towards a parent, guardian, or non-police worker as interviewer (Table 6). Overwhelmingly, officers who selected a sworn officer to interview a missing adult $(81 \%, n=13)$ also wanted this for a child $(p=<0.01)$. The majority of officers, who wanted a parent, guardian, or non-police worker to interview a child, also wanted this interviewer for an adult.

The key reason officers gave for choosing a sworn police officer to interview an adult focused on qualifying the need to involve someone else too $(n=9)$. This was alongside a

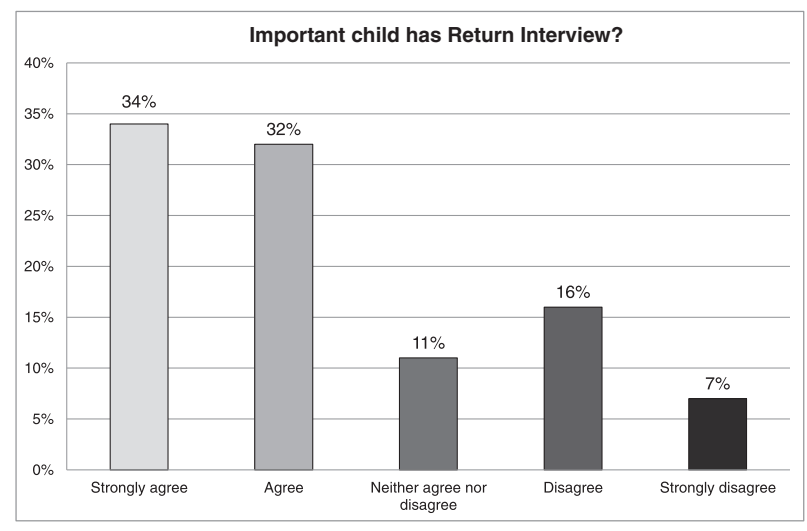

Chart 2. Important children have return interview?

Table 5. Importance of return interview for child - free text themes

\begin{tabular}{|c|c|c|}
\hline $\begin{array}{l}\text { Intelligence gathering } \\
\text { about circumstances }\end{array}$ & $\begin{array}{l}\text { Negative comments } \\
\text { or saying it depends }\end{array}$ & $\begin{array}{l}\text { Welfare or health } \\
\text { of person }\end{array}$ \\
\hline Prevent repeat & Waste of time & $\begin{array}{l}\text { Safeguarding/abuse/Child } \\
\text { Sexual Exploitation }\end{array}$ \\
\hline Why/where went & Someone else's problem & Mental health \\
\hline Document & Depends on circumstances & Build rapport/help \\
\hline Locate in the future & Fail to engage & Discover if victim of crime \\
\hline Intel on misper friends & & Show impact on others \\
\hline \multirow[t]{2}{*}{ Educate } & & Underlying issues \\
\hline & & Welfare/vulnerability \\
\hline
\end{tabular}


Table 6. Gender/choice of interviewer

\begin{tabular}{lcc}
\hline Interviewer & Male officer (\%) & Female officer (\%) \\
\hline Sworn officer & 24 & 73 \\
NHS/social services & 33 & 27 \\
Parent/guardian/non-police & 42 & 0 \\
\hline
\end{tabular}

NHS, National Health Service.

recognition that it depended on the circumstances $(n=4)$. There was also alertness to the intelligence-gathering value of the interview $(n=4)$.

The most popular reason officers gave for selecting a National Health Service (NHS) or social services worker to interview an adult centred on perceiving they were better suited to obtain support for the missing person and provide information to them $(n=6)$. In addition, officers remarked these agencies knew more about the adult's background from records and therefore had better understanding $(n=5)$. Officers linked missing adults with needing professional mental health intervention $(n=4)$. The key reason for an NHS or social services worker interviewing a child was because they would not engage with police because of being scared $(n=3)$.

The most popular reason officers gave for choosing a parent, guardian, or non-police person to interview an adult emphasised that honesty by the missing adult would be encouraged $(n=6)$. Officers further highlighted that interviews need not be by a sworn police officer, or police community support officer $(n=4)$. Qualifying comments included 'Do not want...p police... because they were taking part in illegal activities or they don't want to get anyone else into trouble.' Also, 'We spend to much time looking for missing people, who in most cases are not at risk or vulnerable.' Key reasons officers gave for choosing a parent, guardian, or non-police person for a child acknowledged it depended on circumstances $(n=4)$, and the personal knowledge by a guardian helped $(n=3)$. Qualifying comments included 'Social Services or NHS don't do anything else and are useless'. Also, 'Young people close down immediately when they see the uniform... and the whole thing becomes a tick box exercise.'

The majority of officers $(67 \%, n=28)$ stated that missing people were unengaged or very unengaged by the return interview. The mean response was 4.0 (standard deviation 0.883 ). Only one officer thought the missing person was engaged (Chart 3). In giving their reasons, top remarks explained missing people do not want police $(n=11)$, that the missing person was not bothered, or saw interviews as pointless $(n=9)$, or that they had free will and do not want to be told what to do $(n=7)$. Officers also identified that there was distrust of police, and negativity towards them $(n=7)$, and that missing people do not believe the return interview will lead to change or help $(n=7)$ (Table 7). Officers expanded on this to state, 'Probably not a police issue, i.e. more mental health, social, behavioural.' Also, 'They have been missing before, they will go missing again. They... don't care that a lot of resources are spent trying to locate them.'

A significant majority of officers expressed agreement or strong agreement that return interviews were useful in establishing why people went missing $(79 \%, n=33$, mean $=1.86$, standard deviation $=0.751)$; where people went $(85 \%, n=36$, mean $=1.74$, standard deviation $=0.701)$; and helped future investigations $(84 \%, n=36$, mean $=1.62$, standard deviation $=0.764)$. No officer disagreed or strongly disagreed interviews were valuable in these ways (Chart 4). 


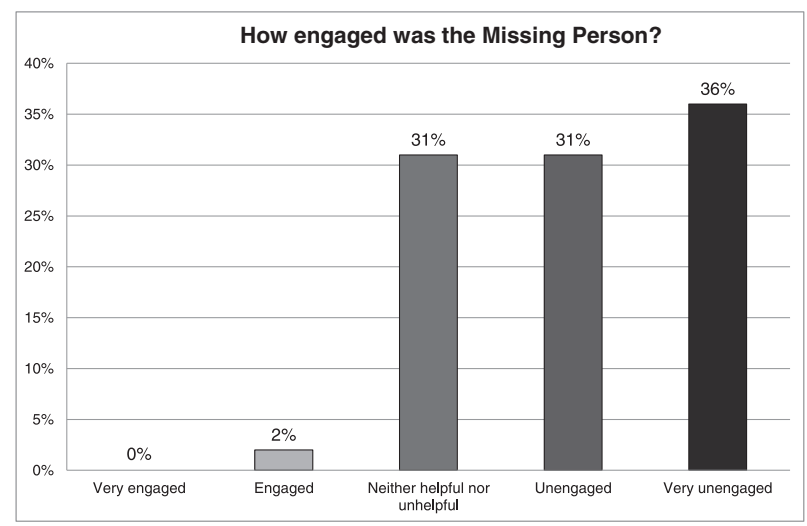

Chart 3. How engaged was the missing person?

Table 7. Remarks for missing person's engagement-free text themes

\begin{tabular}{lll}
\hline Attitude of 'misper' & \multicolumn{1}{c}{ Activity } & \multicolumn{1}{c}{ Social issues } \\
\hline Not bothered & Give game away & Mental health \\
Mistrust police & Involved in bad activity & Drugs \\
Interviewer is a stranger & Lack of interviewer training & Alcohol \\
Free will & & Regular 'service user' \\
Nothing will change & & Personal issues/problems \\
\hline
\end{tabular}

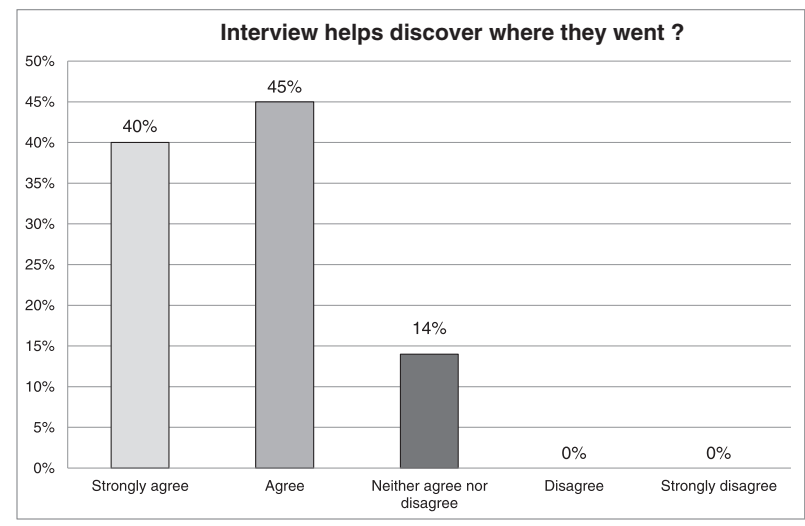

Chart 4. Return interview help find out where went missing?

Officers who supported the effectiveness of return interviews highlighted that they helped identify underlying issues $(n=6)$, helped fill gaps and gave clues or a starting point $(n=6)$, gave intelligence and recorded the episode for the future $(n=6)$, or sometimes helps officers understand $(n=4)$. One officer commented, 'If the subject is wanted in the future... it can provide intelligence on their lifestyle and various addresses.' This positive agreement did begin to unravel, for example, when an officer remarked, 'It helps us understand. However...source of frustration when the reasons aren't being addressed by the appropriate agencies who rely on police to "sort it out".' More dominant remarks contradicted 
previously expressed positivity and focused on a belief missing people will not disclose $(n=27)$, were too vague $(n=9)$, were unengaged $(n=6)$, or that they lied $(n=5)$. An officer went on to explain that missing people "will not open up fully to a police officer, sometimes out of fear of being seen as a "grass". This... prevents officers from being able to fully understand.'

\section{DISCUSSION}

The study has highlighted that return interviews for missing people are frequently featuring in the work of police constables, in the city investigated. This validates what the officers go on to say about their experience. The prevalence of missing people reported repeatedly by officers is supported by the national picture (NCA, 2015) and shows the impact on police resources.

There was statistical significance that female officers in the study were twice as likely as men to be under 36 years old. There was statistical significance that younger officers shouldered the greatest return interview workload. Therefore, women are bearing the greatest burden for conducting interviews. Police managers should cause a diversity review to be conducted, to ensure that female officers are not being marginalised into 'stereotypical roles’ identified by Fielding (1994), Reiner (2000) and Westmarland (2001).

The return interview is crucial to the missing person investigation, yet most officers in the study were not trained on how to conduct interviews. Newiss (2004) and Alys et al. (2013) also highlighted lack of training was an issue. There was statistical significance that the untrained officers in the study had not read missing person policy. Smith and Shalev Greene (2014) found similar unfamiliarity with national and local guidance. The present study found that awareness of the national policy led to better awareness of local policy, driven by specific awareness of vulnerable adults and children. The lack of training and policy awareness by officers demonstrates risk for police managers in ensuring best practice and keeping vulnerable people safe. Therefore, police managers should address this, highlighting the usefulness of return interviews identified from officers themselves in this study, whilst challenging negativity and stereotypes that have been unearthed. The number of officers trained in interviewing vulnerable adults and children should be increased, to better match numbers trained in suspect interviews and support renewed focus by the Home Office on vulnerable and intimidated victims (Ministry of Justice, 2013).

Despite the majority of officers in this study initially stating return interviews were important in the Likert responses, a significant minority disagreed, and many officers later contradicted any optimism in their open remarks. Hedges (2002) found the police viewed missing people as less important than other duties. Significantly as officers become more experienced at interviews (conducting three or more), positivity about them fell. These findings accord with Newiss (1999) who found bias among officers relating to repeatedly missing people. Interview fatigue may be to blame and could be a warning against a dedicated team unless interviewers are rotated. Interestingly, although some officers mentioned safeguarding when responding to return interview importance for children, no officer mentioned safeguarding for adults.

The statistical significance that most female officers in the study selected a sworn police officer as interviewer may indicate favour towards authority figures. Conversely, male officers tended to lean away from sworn police officers as interviewers of adults. This may be because they do not see return interviews of adults as a police role, because of less perceived vulnerability. The significance of officers who selected a sworn officer to interview a missing adult, 
also doing so for children, may indicate a 'closed mind' to non-police options, or a consistent approach to choosing an authority figure. However, this consistent choice of sworn officer was made less emphatic by qualifying it with the need to involve someone else too.

The top reasons for selecting an NHS or social services interviewer of missing people tended to focus on the background knowledge and healthcare skills they could bring, thus acknowledging a wider social issue. It may be that missing people may feel information given to social services, rather than to the police, will less likely lead to them being criminalised. Several officers tended to make a perceived link with mental health issues, which may need further empirical research.

The top reasons for choosing a parent, guardian, or non-police interviewer tended to focus on their personal knowledge of the missing person, but also a perceived trust where a missing adult would confide more readily. Often, officers stated that their police role discouraged openness from missing people.

Participant free text comments relating to children going repeatedly missing often identified return interviews as pointless, which may relate to a feeling of helplessness at solving issues. Dishonesty by missing people featured where police were selected as interviewers, and officers tended to focus on negativity around social services. This is supported by recent research by Bayliss and Quinton (2013). Police managers should consider a multi-agency approach to all return interviews, so that different skill sets, background knowledge, and intelligence could be shared, breaking down barriers between agencies.

Officers overwhelmingly reported the missing person was unengaged by the return interview. This is a critical area to focus upon if any level of success is hoped with investigations. It is crucial that the return interview should be fruitful and seen as worthwhile by the interviewer. With no motivation to do the interview and a sense that little will come from it, useful information will not be revealed. This makes it important to assess how officers might be motivated but moreover, how the police officer themselves might use skills and tools to motivate the missing person. The mixed-team approach advocated by this study could bring innovation. Fresh ideas could challenge the status quo, to bring better engagement from the missing person. This area lends itself to further empirical research especially since post-survey, Local Authorities now have legal responsibility for return interviews for children, within 72 hours.

Officers overwhelmingly agreed that return interviews did establish why someone had gone missing, where they went, and that it helped future investigations. No participant disagreed that interviews were helpful. However, in popular free text responses, officers tended to express a view that missing people did not give information, were vague, or lied. Again, frustration was expressed at the contribution of non-police agencies. This gap between the officers' positive attitude on the surface and deeper negativity needs to be addressed, in order to safeguard vulnerable missing people.

\section{CONCLUSION}

This study has built on sparse existing literature, to identify the frequent prevalence of return interviews of missing people for the police in the English force studied, and the significance of repeat cases to those officers. The strength of the study lies in direct access to an under-explored area of police culture, to highlight attitudes of officers to return interviews and frustration with repeatedly missing people. This is important given the estimated cost of an average investigation, in a time of budget cuts. It is clear that gender is an important 
area in terms of the disproportionate burden on female officers to conduct return interviews. Significant lack of training and awareness of national and local policy has been identified. This links to findings that despite renewed pressure from the Ministry of Justice to improve the response to vulnerable and intimidated witnesses, only a few officers were trained in this area. This study has shown the majority of officers agreed or strongly agreed that it was important to conduct a return interview for missing people. But significantly, those most experienced at return interviews were most likely to disagree they were important. The study has also highlighted inconsistencies to initial positivity. There was also stereotyping by officers, especially for 'streetwise' children. There was a lack of understanding among officers that adults may need safeguarding. The study found significance in choice of interviewer, such as female officers overwhelmingly selecting a police officer to conduct interviews. Selection of other interviewers by participants focused on mistrust of police, and entrenched stances against social services. There was significance between a participant's selections of interviewer for a missing adult, against who should interview a child. Officers overwhelmingly reported the missing person was unengaged by the return interview process, especially in repeat cases. Overwhelmingly, officers expressed agreement that return interviews were useful, but free text responses contradicted this with pessimism.

There were some limitations to the study. Although the sample of 50 officers is acceptable, there was some survey fatigue so that by the final questions, eight officers stopped responding fully. The response rate from the available population of constables was only $12 \%$, but this can be explained by the busy nature of the role being explored. The free text responses are open to the interpretation of the authors, one of whom is a serving police officer, and so 'insider' bias must be considered. This is mitigated by data saturation and the availability of raw responses on application. Lastly, officers were responding within their workplace, so despite information provided to officers assuring confidentiality, and the study meeting ethical approval, respondents may have 'held back' controversial views.

The findings of this study could represent a challenge to UK police leaders, to improve their response to return interviews, thereby keeping missing people more safe. The view by one participant that '98\% of "mispers" are a waste of time' should be unpicked and challenged. Further research of return management is recommended encompassing more than one police force, to reach more officers and capture regional variations particularly looking at return interview compliance for children, and the gap in statutory responsibility toward adults.

\section{REFERENCES}

ACPO (2013). Interim guidance on the management and investigation of missing persons 2013. Ryton: College of Policing.

Alys, L., Massey, K., \& Tony, S. (2013). Investigative decision making: Missing people and sexual offences, crossroads to an uncertain future. Journal of Investigative Psychology and Offender Profiling, 10, 140-154 Wiley Online Library.

Bayliss, A., \& Quinton, P. (2013). Risk, bureaucracy and missing persons: An evaluation of a new approach to the initial police response. Ryton: College of Policing.

Biehal, N., Mitchell, F., \& Wade, J. (2003). Lost from view: Missing persons in the UK. Bristol: The Policy Press.

Brown, S., \& Wain, N. (2009). Vanishing point. Police Review, $20^{\text {th }}$ February.

Burgess, C., Malloch, M., Mitchell, F., Chan, V., Euson, J., \& Murray, L. (2010). Grampian police return home welfare interview pilot for young runaways: Pilot evaluation. Stirling: University of Stirling. 


\section{F. Harris and K. Shalev Greene}

Dando, C. J., \& Bull, R. (2011). Maximising opportunities to detect verbal deception: Training police officers to interview tactically. Journal of Investigative Psychology and Offender Profiling, 8, 189-202. DOI:10.1002/jip.145.

Fielding, N. (1994). Cop canteen culture. Just boys doing business, 46-63.

Fyfe, N., Stevenson, O., \& Woolnough, P. (2015). Missing persons: The processes and challenges of police investigation. Policing and Society: An international Journal of Research and Policy Routledge. DOI: 10.1080/10439463.2014.881812

Haberfeld, M. R. (2002). Critical issues in police training. New Jersey: Prentice Hall Publishing.

Hayden, C., \& Goodship, J. (2013). Children reported 'missing' to the police: Is it possible to 'risk assess' every incident? British Journal of Social Work. DOI:10.1093/bjsw/bet150. Oxford University Press.

Hedges, C. (2002). Missing you already: A guide to the investigation of missing persons. Report for the Home Office and Thames Valley Police.

Holmes, L. (2014). When the search is over. Reconnecting missing children and adults. Report for 'Missing People'.

Home Office 2013. Police workforce in England \& Wales. Retrieved 11 December 2014 from: https://www.gov.uk/government/publications/police-workforce-england-and-wales-31-march-2013/ police-workforce-england-and-wales-31-march-2013

IPCC (2014). Learning the lessons: Bulletin 22. November 2014. Retrieved on $28^{\text {th }}$ January 2015 from: https://www.ipcc.gov.uk/sites/default/files/Documents/learning-the-lessons/22/Bulletin_22_Case5.pdf

Memon, A., Bull, R., \& Smith, M. (1995). Improving the quality of the police interview: Can training in the use of cognitive techniques help? Policing and Society: An International Journal of Research and Policy, 5(1), 53-68. DOI:10.1080/10439463.1995.9964710.

Ministry of Justice (MoJ) (2013). The witness charter: Standards of care for witnesses in the criminal justice system. London: Home Office.

NCA (2015). Missing persons: Data and analysis 2013/14. UK Missing Persons Bureau. Retrieved $19^{\text {th }}$ December 2015 from: http://www.missingpersons.police.uk/en/resources/missing-personsdata-analysis-2013-14

Newiss, G. (1999). Missing presumed...? The police response to missing persons Police Research Series Paper 114. London: Home Office.

Newiss, G. (2004). Estimating the risk faced by missing persons: A study of homicide victims as an example of an outcome-based approach. International Journal of Police Science \& Management, $6(1), 27-36$.

Newiss, G. (2011). Learning from fatal disappearances. London: A report by Missing People.

Newman, C. (1989). Young runaways: Finding from Britain's first safe house. London: The Children's Society.

Payne, M. (1995). Understanding 'going missing': Issues for social work and social services. British Journal of Social Work, 25, 333-348.

Rees, G. 2011. 'Still Running 3'. The Children's Society. Retrieved 10 December 2011 from http:// makerunawayssafe.org.uk/sites/default/files/tcs/u24/Still-Running-3_Full-Report_FINAL.pdf

Reiner, R., \& Newburn, T. (2000). Police research. Oxford University Press.

Shalev, K. \& Pakes, F. (2013). The cost of missing person investigations: Implications for current debates. Policing, 8(1), 27-34. DOI:10.1093/police/pat036.

Shalev, K., Schaefer, M., \& Morgan, A. (2009). Investigating missing person cases: How can we learn where they go or how far they travel? International Journal of Police Science \& Management, 11(2), 123-129.

Smith, R., \& Shalev Greene, K. (2014) High risk? attitudes to the risk assessment process in missing person investigations. University of Portsmouth. Retrieved on 28 January 2015 from: http://www.port.ac. uk/media/contacts-and-departments/icjs/csmp/Attitude-to-the-risk-assessment-process--final.pdf

Snook, B., Luther, K., Quinlan, H., \& Milne, B. (2012). Let 'em talk!: A field study of police questioning practices of suspects and accused persons. Criminal Justice and Behavior, 29(10), 1328-1339. ISSN 0093-8548 10.1177/0093854812449216.

Tarling, R., \& Burrows, J. (2004). The nature and outcome of going missing: The challenge of developing effective risk assessment procedures. International Journal of Police Science \& Management, 6(1), 16-26.

Watzlawick, P. (1966). A structured family interview. Family Process, 5, 256-271. DOI:10.1111/ j.1545-5300.1966.00256.x.

Westmarland, L. (2001). Gender and Policing: Sex. Power and Police Culture. Devon: Willan. 